\title{
Understanding the limits of parametrial resection in radical hysterectomy: a randomized controlled trial
}

\author{
Fortunato Genovese ${ }^{1}$, Stefano Siringo ${ }^{1}$, Attilio Tuscano ${ }^{2}$, Ferdinando Antonio Gulino ${ }^{3}$, \\ Francesco Cannone ${ }^{3}$, Vito Leanza ${ }^{1}$, Francesco Cosentino ${ }^{4}$, Stefano Palomba ${ }^{2}$, Marco Antonio Palumbo ${ }^{1}$ \\ ${ }^{1}$ UOC of Obstetric and Gynecologic Pathology, Department of General Surgery and Medical Surgical Specialities, San Marco Hospital, \\ University of Catania, Catania, Italy \\ ${ }^{2}$ UOC of Obstetrics and Gynaecology, G.O.M. Bianchi-Melacrino-Morelli, Reggio Calabria, Italy \\ ${ }^{3}$ Azienda di Rilievo Nazionale e di Alta Specializzazione (ARNAS) Garibaldi, Catania, Italy \\ ${ }^{4}$ University of Catania Gynecology Oncology, Gemelli Molise, Università Cattolica Sacro Cuore, Campobasso, Italy
}

\begin{abstract}
Introduction: The aim was to evaluate whether adding specific educational medical illustrations may help gynecologists to better understand the limits of parametrial resection in radical hysterectomy from type A to type C2. Study Design: randomized controlled trial.

Material and methods: Institute of Obstetric and Gynecologic Pathology, University of Catania, Italy. Materials and methods: 30 senior Obstetrics and Gynecology (Ob/Gyn) residents and 30 general Ob/Gyn consultants were enrolled in the study, and randomized to two groups of 15 people (group A and group B). Both groups had a copy of the article on the Querleu-Morrow Classification of Radical Hysterectomy (2017) for reading comprehension. Group B also had 10 unpublished medical illustrations, prepared for this paper. After one month the level of self-perceived understanding related to parametrectomy limits in radical hysterectomy was evaluated in both groups using a numeric visual analog scale, where each participant evaluated his degree of comprehension. The data were statistically analyzed using the $U$ Mann-Whitney test.

Results: Group A participants (only article) had a lower level of comprehension of parametrectomy limits compared to group B participants (article plus drawings). The difference between the mean scale score, reported by group $A$, equal to $5.9 \pm 1.4$, and that reported by group $B$, equal to $7.2 \pm 1.5$, was statistically significant $(p<0.01)$. Conclusions: The results of this study suggest that educational materials, such as the proposed drawings, may help both Ob/Gyn consultants and residents to better understand the relationship between the extent of parametrial resection and cervical disease severity, and the related postoperative complications.
\end{abstract}

Key words: numeric visual analog scale, paracervix, parametrectomy, pelvic anatomy, radical hysterectomy, subperitoneal spaces.

\section{Introduction}

Cervical cancer treatment has always represented a challenge for surgeons, radiotherapists, radiologists and medical oncologists [1]. It is the twelfth most frequent cancer in women in developed countries, and patients may experience changes in their sexual functioning and quality of life resulting from the cancer itself and its treatment [2]. If on the one hand surgery and adjuvant radio- and chemotherapy are able to be curative in the majority of cases at the early stage, on the other hand the young age of affected women determines the exposure of patients to the long-term consequences of treatments, affecting health and different aspects of the quality of life, which can be disrupted by urinary, gastrointestinal, neurologic, reproductive, and sexual side effects primarily related to surgery and radiotherapy [3]. The purpose of the surgical treatment, is that of removing, with the exception of microinvasion, beside the cervix the connective tissue around it and the upper vagina, known as paracolpos or paracolpium, with or without lymphadenectomy in a measure progressively greater depending on the size, aggressiveness of the tumor and lymph node status $[1,4,5]$. Preoperative conization plays a potentially protective role in patients with an IB1 tumor [6].

Such connective tissue in the present paper is called in general parametrium, which may not be anatomically correct, but since this term has gained an unreplaceable place in the mind of most gynecologic surgeons, 
Table 1. Indications for different classes of radical hysterectomy - Guidelines 2018 European Society of Gynaecological Oncology

\begin{tabular}{lcccc}
\hline Risk group & Tumor size & LVSI & Stromal invasion & Type of radical hysterectomy \\
\hline Low risk & $<2 \mathrm{~cm}$ & Negative & Inner $1 / 3$ & B1 (A) \\
\hline Intermediate risk & $\geq 2 \mathrm{~cm}$ & Negative & Any & B2 (C1) \\
\hline Intermediate risk & $<2 \mathrm{~cm}$ & Positive & Any & B2 (C1) \\
\hline High risk & $\geq 2 \mathrm{~cm}$ & Positive & Any & C1 (C2) \\
\hline
\end{tabular}

LVSI - lymphovascular space invasion

the Authors continue to use it in its extensive meaning. At the same time it is important to precise that according to the Terminologia Anatomica [7] the term parametrium should be referred to the cranial portion (above the ureter) of the cardinal ligament (unofficial term), instead paracervix should be related to the caudal portion (below the ureter) of the same ligament.

The reason to extend the resection to the surrounding parametrium is based on the fact that the more voluminous and poor differentiated is the tumor, the higher is the chance that the tissue around the cervix and upper vagina is infiltrated by neoplastic cells [1].

In order to define and standardize the limit of such a resection in relationship with tumor grade and stage, clinicians had to balance the risks of surgery with the necessity to excise an amount of parametrium adequate to ensure clear margins ( $>3 \mathrm{~mm}$ ) [8].

Based on the amount of resected parametrium various classes of radical hysterectomy have been developed, from the old Piver-Rutlege-Smith [9] to the most recent Querleu-Morrow classification [10]. Recent recommended clinical indications [1] for such operations are reported in Table 1.

The description of radical hysterectomy given in the current literature is more or less directed to surgeons specialized in gynecologic oncology. The authors wanted to evaluate whether adding specific educational materials (medical illustrations created ad hoc) to the reading comprehension of the latest Querleu-Morrow Classification of radical hysterectomy [11] may help $\mathrm{Ob} / \mathrm{Gyn}$ residents and general Ob/Gyn attendees to better understand the limits of parametrial resection in radical hysterectomy from type $\mathrm{A}$ to type $\mathrm{C} 2$.

\section{Material and methods}

On the basis of the necessary anatomical premises (see Appendix 2), the authors asked a medical illustrator to prepare two schematic topographic pictures of the female pelvis (Fig. 1, 2), where ideally all sub-peritoneal spaces are dissected and all parametrium components, dorsal (posterior), ventral (anterior) and lateral (paracervix), are represented and differentiated from each other using a color code for each of them.

The extent of parametrial resection which characterizes each type of radical hysterectomy taking into consideration $\mathrm{A}, \mathrm{B} 1$ and $\mathrm{B} 2, \mathrm{C} 1$ and $\mathrm{C} 2$, according to the

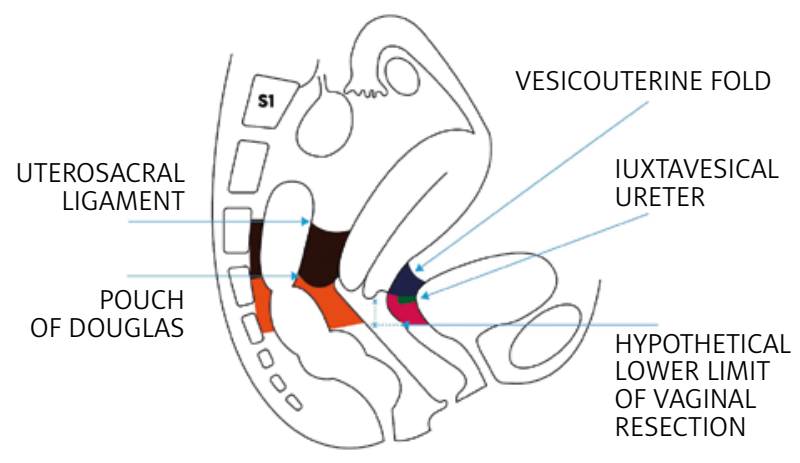

Fig. 1. Schematic representation of dorsal and ventral parametrium in a paramedian sagittal section of the female pelvis (imagined after dissection of all subperitoneal spaces and going approximately through one of the bladder pillars and the omolateral uterosacral ligament)

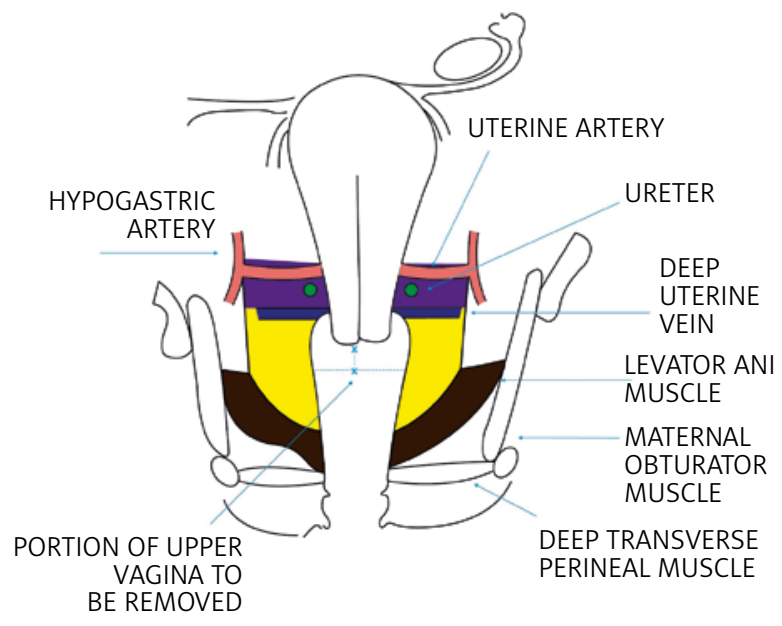

Fig. 2. Schematic representation of lateral parametrium (both sides) in a coronal section of the female pelvis going through the crossing of the uterine artery with the ureter (imagined after dissection of all subperitoneal spaces with the uterus placed in upward traction)

latest Querleu-Morrow classification of radical hysterectomy [11], is indicated in Figures $3-10$ by coloring in gray the corresponding portions of ventral, dorsal and lateral parametrium, which needs to be removed.

In order to establish whether these 10 drawing (Fig. 1-10) may have didactic value, 30 senior Ob/Gyn residents and 30 general Ob/Gyn attending physicians were enrolled as participants in a randomized controlled trial. The participants were randomly allotted 


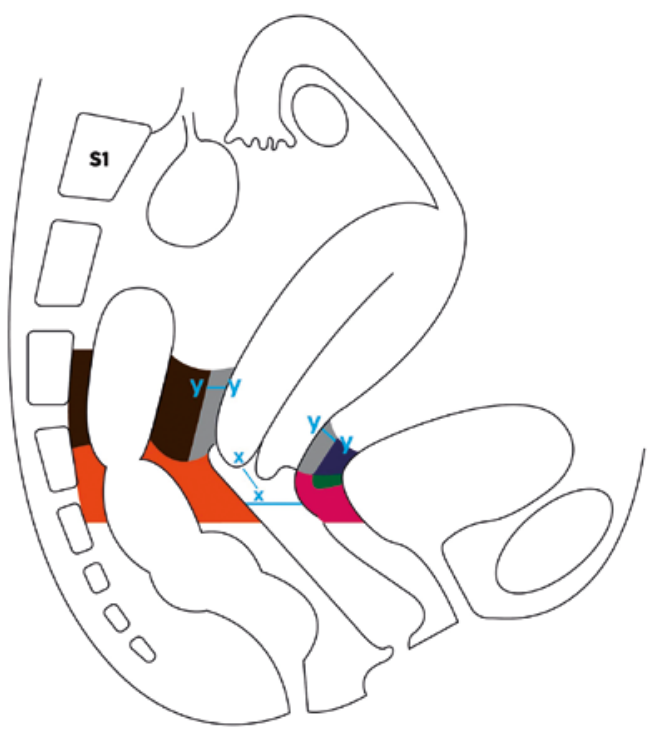

Fig. 3. Limits of resection of the dorsal and ventral parametrium in type $A$ radical hysterectomy (the area of parametrium to be excised is colored in grey, the dissection of the Okabayashi space is not necessary)

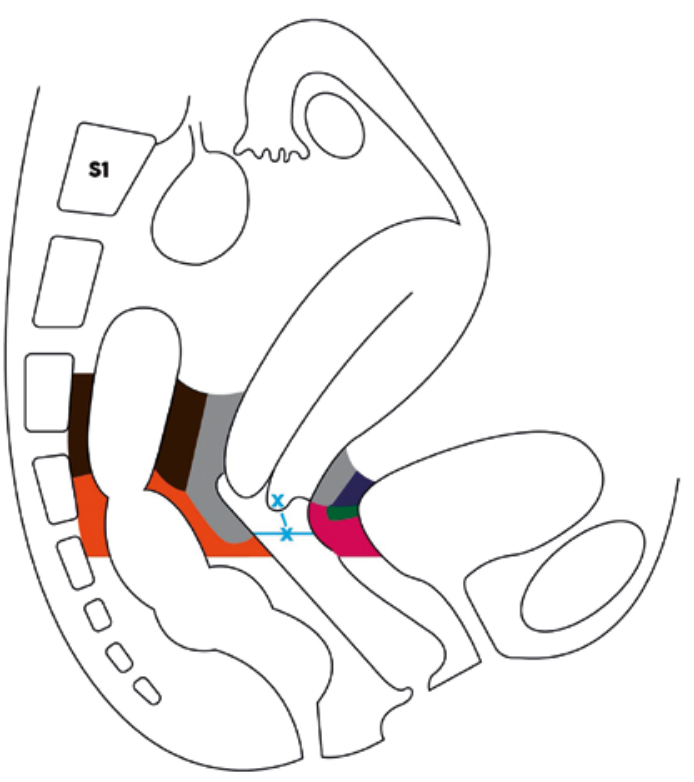

Fig. 5. Limits of resection of the dorsal and ventral parametrium in type B1 and B2 radical hysterectomy. Approximately half of the dorso-ventral length of the dorsal (except sacral attachments) and ventral parametrium (only upper portion) should be removed.

two groups, each made up of an equal number of residents and attending physicians, defined as group $A$ and group $\mathrm{B}$. The recruitment and randomization process required 2 months, from July $1^{\text {st }}$ to August 30, 2020.

The group A participants were emailed a letter (see Appendix 1) with only a copy of the article) [11] attached for reading comprehension, while the group $B$

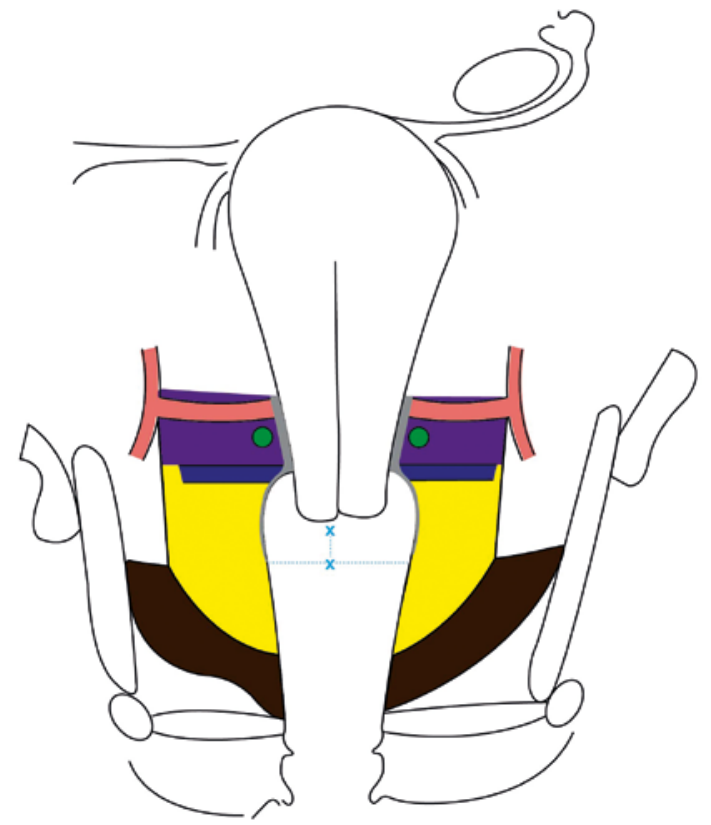

Fig. 4. Limits of resection of the lateral parametrium (paracervix) in type A radical hysterectomy (the area of parametrium to be excised is colored in grey)

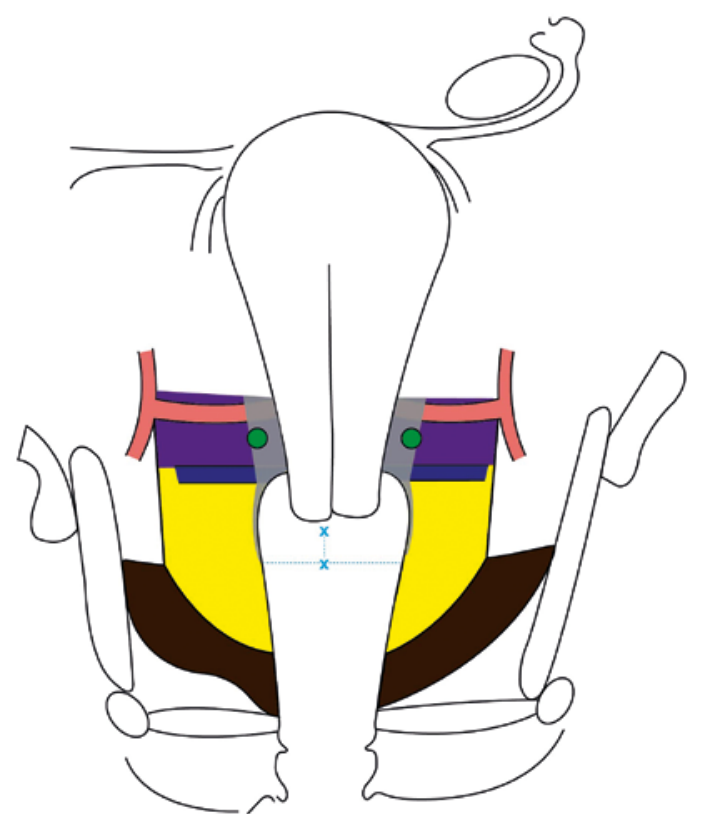

Fig. 6. Limits of resection of the lateral parametrium (paracervix) in type $B 1$ and $B 2$ radical hysterectomy

participants received, beside the copy of the article, the 10 unpublished medical illustrations prepared on the basis of the article, as a supposed didactic aid.

A brief review of the pertinent pelvic anatomy provided by the authors for prompt consultation (see Appendix 2) was also attached to the email sent to both groups. 


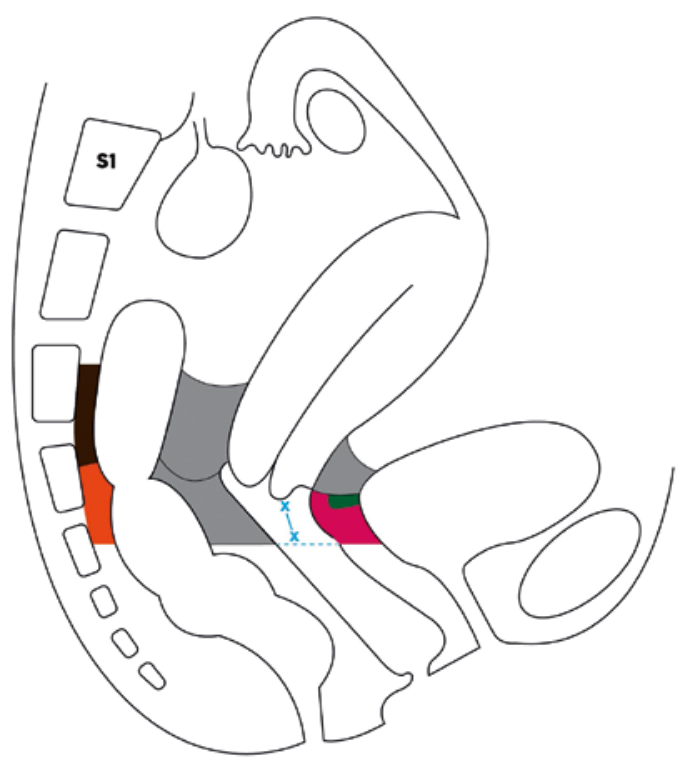

Fig. 7. Limits of resection of the dorsal and ventral parametrium in type $\mathrm{C} 1$ radical hysterectomy

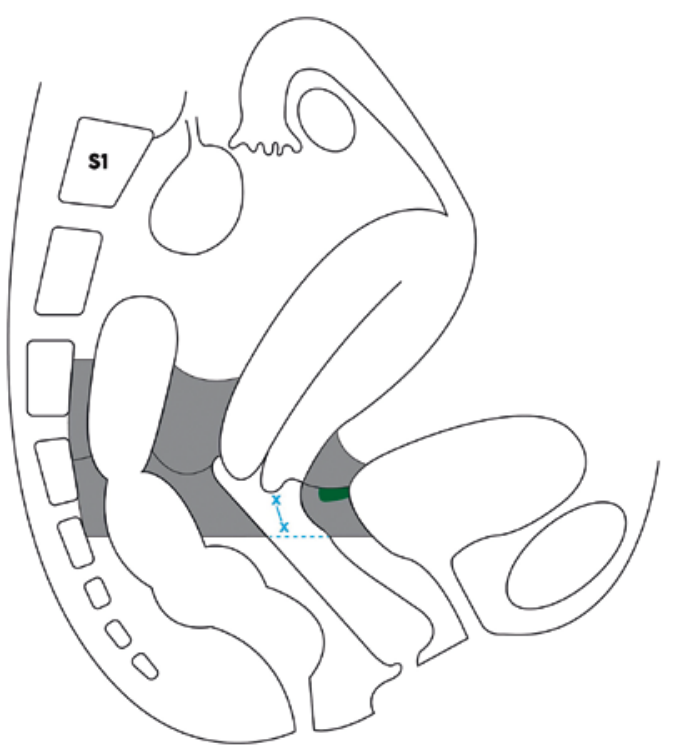

Fig. 9. Limits of resection of the dorsal and ventral parametrium in type C2 radical hysterectomy (the area of parametrium to be excised is colored in grey, the dissection of the medial pararettal space, Okabayashi space, is omitted)

The level of understanding of parametrectomy limits in various types of radical hysterectomy was tested in both groups by asking the participants to rate their self-perceived comprehension on a numeric scale graduated from 0 to 10, attached to the emails (see Appendix 1) sent to both groups.

It is true that in general the level of comprehension in students is tested by administering them multiple choice questionnaires on specific subjects [12] whereas a VAS (visual analog scale) is generally used to self-as-

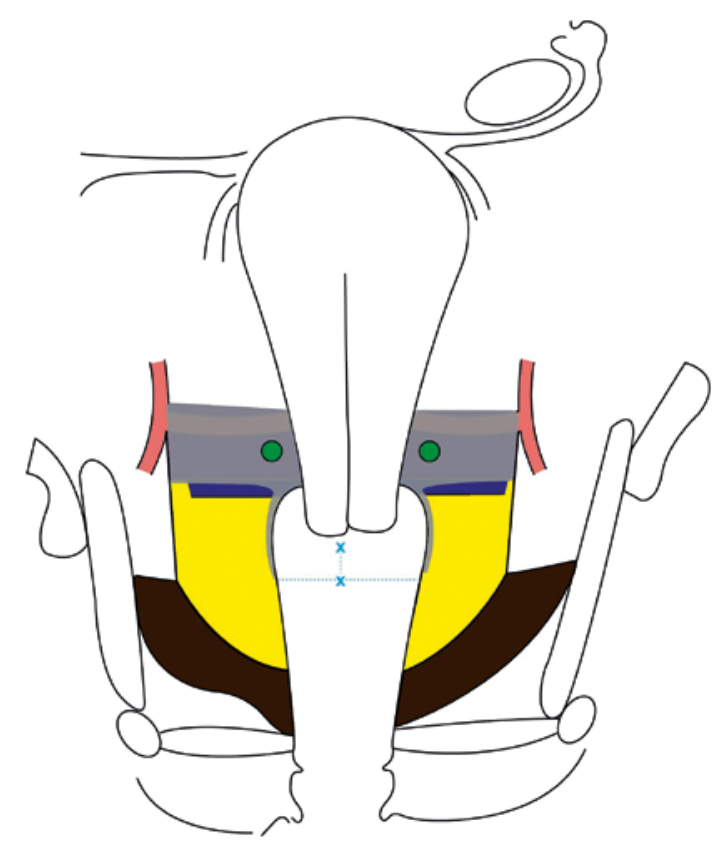

Fig. 8. Limits of resection of the lateral parametrium (paracervix) in type $\mathrm{C} 1$ radical hysterectomy

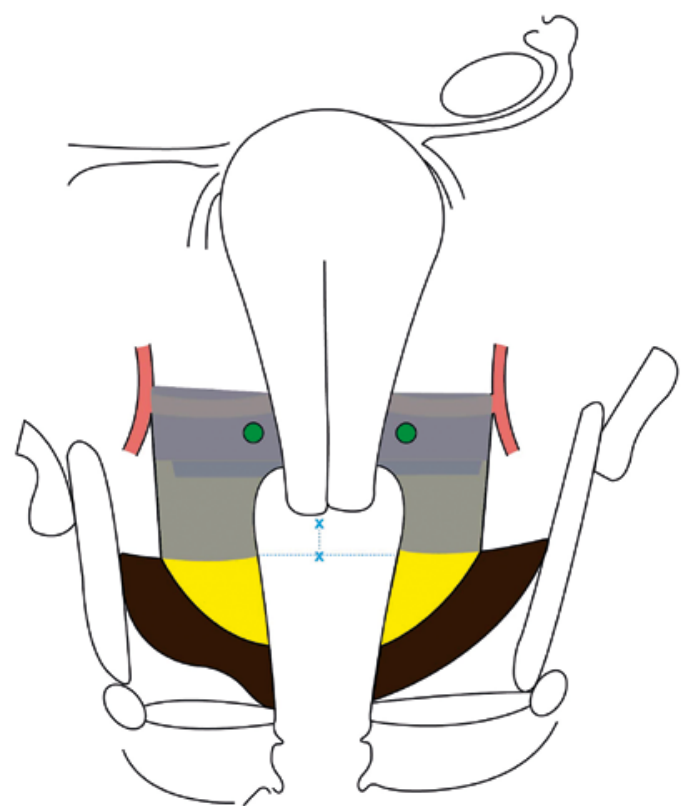

Fig. 10. Limits of resection of the lateral parametrium (paracervix) in type $\mathrm{C} 2$ radical hysterectomy (the area of parametrium to be excised is colored in grey)

sess pain [13] and/or to measure anxiety or pruritus $[14,15]$. However, there are examples in the literature where a VAS has been used for self-assessment of a specific subject understanding [16-18].

Each study participant, after filling out the scale (see Appendix 1), was invited to send it back to the authors within two months from its receipt (sometimes a telephone call, about ten days before the end of the allowed period, was made to solicit an answer). All answers were received by October $30^{\text {th }} 2020$. Furthermore, in order to 


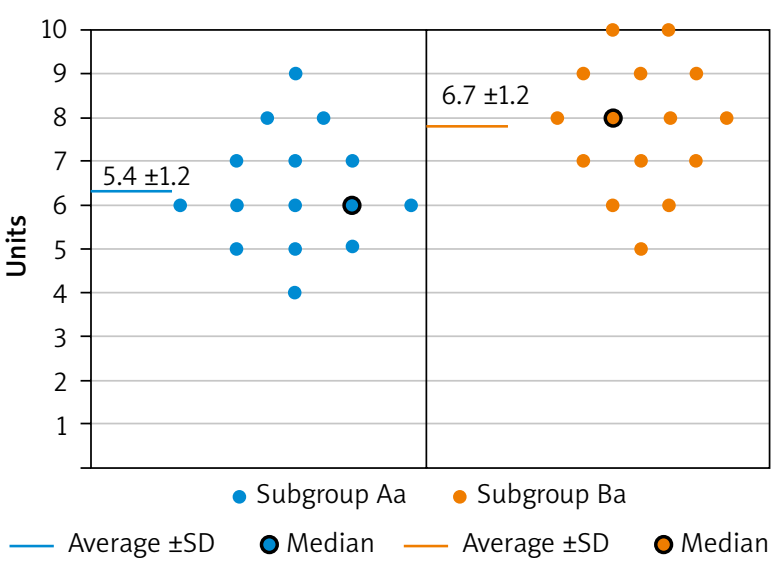

Fig. 11. Scores distribution and comparison between the 2 subgroups of Obstetrics and Gynecology attending physicians

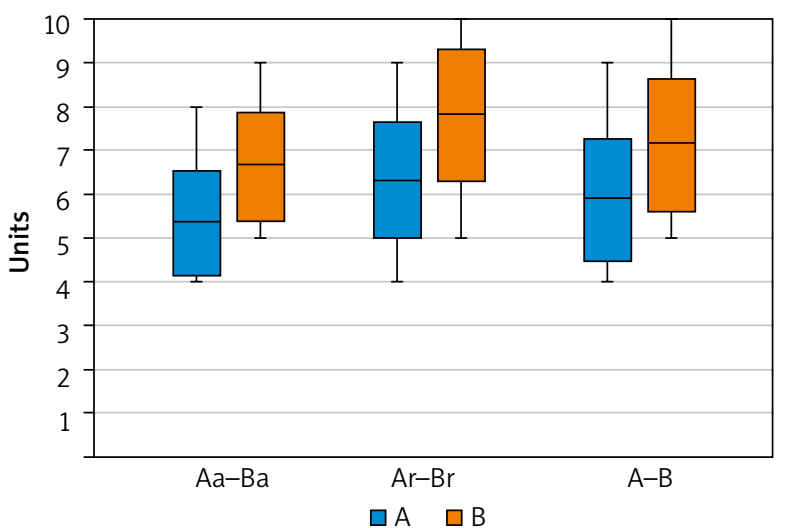

Fig. 13. Comparison of score averages $( \pm S D)$ between subgroups and groups $A$ and $B$

compare results also between homogeneous categories of participants group A was divided into 2 subgroups, identified as subgroup Ar (made only by senior Ob/Gyn residents) and subgroup Aa (made only by general Ob/Gyn attending physicians), and similarly group $\mathrm{B}$ was divided into subgroup $\mathrm{Br}$ and subgroup $\mathrm{Ba}$. The data obtained were statistically analyzed using $U$ Mann-Whitney test. The level of statistical significance was defined by a $p$ value $\leq 0.01$ with a $99 \%$ confidence interval.

\section{Results}

All the recruited participants adhered to the protocol and mailed their answer to the authors within the allowed month.

The numeric analogue scale scores, obtained by each participant in the study, are reported for every different subgroup in Figures 11 and 12. As shown in Figure 13 and Table 2, the average understanding value for both attending physicians $(5.4 \pm 1.2)$ and residents $(6.3 \pm 1.3)$ is significantly lower $(p<0.01)$ in subgroups Aa and Ar compared with that in subgroups $\mathrm{Ba}(6.7 \pm 1.2)$ and $\operatorname{Br}(7.8 \pm 1.5)$. Similarly the cumulative average score of

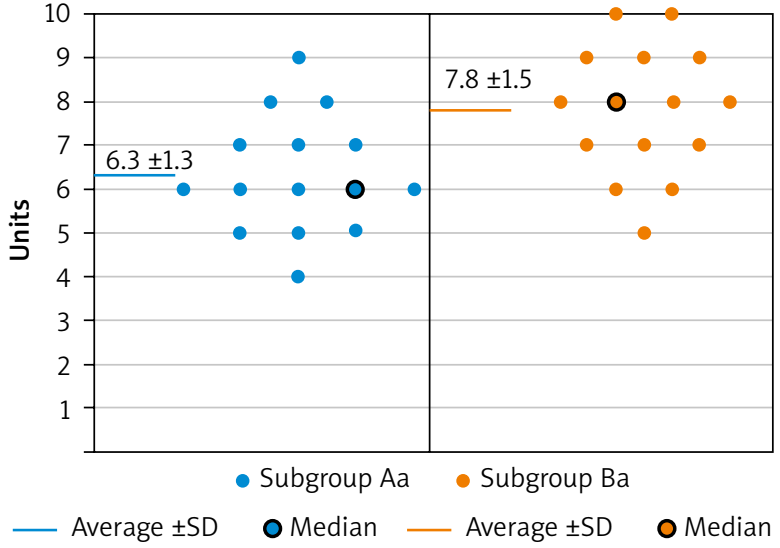

Fig. 12. Scores distribution and comparison between the 2 subgroups of senior Obstetrics and Gynecology residents

Table 2. Average score comparison between subgroups $A a$ and $\mathrm{Ba}, \mathrm{Ar}$ and $\mathrm{Br}$, and groups $\mathrm{A}$ and $\mathrm{B}$

\begin{tabular}{lcc}
\hline $\begin{array}{l}\text { Subgroup Aa } \\
\text { average score }\end{array}$ & $\begin{array}{c}\text { Subgroup Ba average } \\
\text { score }\end{array}$ & $p$ \\
\hline $5.4 \pm 1.2$ & $6.7 \pm 1.2$ & 0.007 \\
\hline $\begin{array}{l}\text { Subgroup Ar average } \\
\text { score }\end{array}$ & $\begin{array}{c}\text { Subgroup Br average } \\
\text { score }\end{array}$ & $p$ \\
\hline $6.3 \pm 1.3$ & $7.8 \pm 1.5$ & 0.007 \\
\hline $\begin{array}{l}\text { Group A average } \\
\text { score }\end{array}$ & Group B average & $p$ \\
\hline $5.9 \pm 1.4$ & score & \\
\hline
\end{tabular}

residents and attending physicians, taken together, seen in group A $(5.9 \pm 1.4)$ is also significantly lower $(p<0.01)$, than that found in group $B(7.2 \pm 1.5)$.

\section{Discussion}

Procedures such as radical hysterectomy today are generally performed by gynecologic surgeons trained in gynecologic oncology, and therefore such didactic illustrations may be seen as redundant and superfluous in certain environments; however, considering that parametrectomy is the main cause of postoperative complications [1, 19], both the general Ob/Gyn attending physicians and the Ob/Gyn residents often deal with the patient in the immediate and/or subsequent postoperative period, and that, sometimes, the patient returns to them for clinical follow-up, the authors think that the 2 aforementioned professional figures deserve a clearer comprehension of the postoperative clinical implications correlated with the extent of parametrium removal which characterizes each type of radical hysterectomy.

Undoubtedly the results of this study show that adding the 10 graphs to the simple reading of the article on the classification of radical hysterectomy [11] ameliorates significantly the level of comprehension of parametrectomy extent in both residents and general 
attending physicians and this seems to, somehow, fulfil the author's study objective.

Nevertheless, the authors are aware that the present study has a few limitations, such as the limited number of participants, the fact that the drawings are based on their interpretation of Querleu's article, and that, in other words, the illustrations proposed, even if considered as faithful to the text, are not validated by the article's authors, and, last but not least, the difficulty to objectively measure the level of understanding of the participants, measured simply based on a numeric analogous scale score.

Furthermore, the study has at least 2 forms of bias. The first, more important one is that the self-perceived understanding of parametrectomy limits measured in both groups of participants with the visual analog scale does not necessarily reflect a real improvement in comprehension. The truth of the matter is that this type of understanding is hard to test: even all the correct answers to a hypothetical multiple choice questionnaire do not guarantee a real understanding of this specific subject; the authors think that this particular type of comprehension probably could be better verified only by an expert gynecologic oncology surgeon either in the operating room or in the cadaver dissection room.

The other bias, less relevant, is that an improvement in comprehension is in general expected when the amount of educational material on a specific subject is increased. However, such improvement is not automatically achieved and sometimes the added educational resource not only does not ameliorate comprehension, but it even has a detrimental effect on it.

Despite the aforesaid confounders and bias, the authors maintain that their results may, at least, encourage and stimulate future and better didactic efforts in the direction of making the anatomical and functional meaning of parametrectomy and its clinical relevance (in relation to the various classes of radicality) more understandable for general gynecologists or future professionals, not necessarily going to specialize in gynecologic oncology.

\section{Conclusions}

The authors, on the basis of the appreciation expressed by residents and attending physicians for their didactic initiative, think that the improvement in knowledge triggered by the graphs will positively affect patient care and that further simplified educational models, either two- or three-dimensional, should be developed in the near future to better serve this purpose. Further illustrations like those presented could be used by clinicians at the time of informed consent to give also patients affected by cervical cancers a better idea of the type of surgery which they will undergo.

\section{Disclosure}

The authors report no conflict of interest.

\section{References}

1. Cibula D, Pötter R, Planchamp F, et al. The European Society of Gynaecological Oncology/European Society for Radiotherapy and Oncology/European Society of Pathology Guidelines for the Management of Patients With Cervical Cancer. Int J Gynecol Cancer 2018; 28: 641-655.

2. Laganà AS, la Rosa VL, Fanale D, Vitale SG. Comment on: survey of cervical cancer survivors regarding quality of life and sexual function. J Cancer Res Ther 2017; 13: 598-599.

3. Laganà AS, Garzon S, Raffaelli R, Frangez HB, Lukanovic D, Franchi M. Vaginal stenosis after cervical cancer treatments: challenges for reconstructive surgery. J Invest Surg 2021; 34: 754-755.

4. Casarin I, Bogani G, Piovano E, et al. Survival implication of lymphadenectomy in patients surgically treated for apparent early-stage uterine serous carcinoma. J Gynecol Oncol 2020; 31: e64.

5. Freytag D, Pape J, Dhanawat J, et al. Challenges posed by embryonic and anatomical factors in systematic lymphadenectomy for endometrial cancer. J Clin Med 2020; 9: 4107.

6. Casarin J, Bogani G, Papadia A, at al. Preoperative conization and risk of recurrence in patients undergoing laparoscopic radical hysterectomy for early stage cervical cancer: a multicenter study. J Minim Invasive Gynecol 2021; 28: 117-123.

7. Ercoli A, Delmas V, Fanfani F, et al. Terminologia Anatomica versus unofficial descriptions and nomenclature of the fasciae and ligaments of the female pelvis: a dissection-based comparative study. Am J Obst Gynecol 2005; 193: 1565-1573.

8. Bisseling KC, Bekkers RL, Rome RM, Quinn MA. Treatment of microinvasive adenocarcinoma of the uterine cervix: a retrospective study and review of the literature. Gynecol Oncol 2007; 107: 424-430.

9. Piver MS, Lee JY. The $21^{\text {st }}$ century role of Piver type II hysterectomy in FIGO stage IA, IB cervical cancer: a personal perspective. Eur J Gyneacol Oncol 2008; 29: 109-113.

10. Querleu D, Morow CP. Classification of radical hysterectomy. Lancet Oncol 2008; 9: 297-303.

11. Querleu D, Cibula D, Abu-Rustum NR. 2017 update on the querleumorrow classification of radical hysterectomy. Ann Surg Oncol 2017; 24: 3406-3412.

12. Moss E. Multiple choice questions: their value as an assessment tool. Curr Opin Anaesthesiol 2001; 14: 661-666.

13. Hjermstad MJ, Fayers PM, Haugen DF, et al. Studies comparing numerical rating scales, verbal rating scales, and visual analogue scales for assessment of pain intensity in adults: a systematic literature review. J Pain Symptom Manag 2011; 41: 1073-1093.

14. Purcell-Jones JMA, Haasbroek M, van der Westhuizen JL, Dyer RA, Lombard CJ, Duys RA. Overcoming language barriers using an information video on spinal anesthesia for cesarean delivery: implementation and impact on maternal anxiety. Anesth Analg 2019; 129: 1137-1143.

15. Keir ST, Calhoun-Eagan RD, Swartz JJ, Saleh OA, Friedman HS. Screening for distress in patients with brain cancer using the NCCN's rapid screening measure. Psycho Oncol 2008; 17: 621-625.

16. Kennedy G, Rea JNM, Rea IM. Prompting medical students to self-assess their learning needs during the ageing and health module: a mixed methods study. Med Edu Online 2019; 24: 1579558.

17. Bensoussan L, Collado H, Viton JM, Delarque A. Should European PRM residents be taught in English? The experience of the European school Marseille. Ann Phys Rehabil Med 2009; 52: 729-745.

18. Hogan D, di Martino T, Liu J, Mastro KA, Larson E, Carter E. Video-based education to reduce distress and improve understanding among pediatric MRI patients: a randomized controlled study. J Pediatr Nurs 2018; 41: 48-53.

19. Lee SH, Cho KJ, Ko MH, Cho HY, Lee KB, Lim S. Factors associated with parametrial involvement in patients with stage IB1 cervical cancer: who is suitable for less radical surgery? Obst Gynecol Sci 2018; 61: 88-94.

20. Ceccaroni M, Ceccarello M, Clarizia R, Roviglione G. Anatomia chirurgica della pelvi femminile. Trattato di chirurgia ostetrica e ginecologica. Italy: Edra 2019. 
21. Einarsson J, Wattiez A. Minimally invasive gynecologic surgery: evidence-based laparoscopic, hysteroscopic and robotic surgeries. London: JP Medical 2016.

22. Yabuki Y, Asamoto A, Hoshiba T, Nishimoto H, Satou N. A new proposal for radical hysterectomy. Gynecol Oncol 1996; 62: 370-378.

23. Yabuki Y, Asamoto A, Hoshiba T, Nishimoto H, Nishikawa Y, Nakajima T. Radical hysterectomy: and anatomic evaluation of parametrial dissection. Gynecol Oncol 2000; 77: 155-163.

24. Tribos JB, Maas CP, Deruiter MC, Peters AA, Kenter GG. A nerve-sparing radical hysterectomy: guidelines and feasibility in Western patients. Int J Gynecol Cancer 2001; 11: 180-186.

25. Nakamura M, Tanaka K, Hayashi S, et al. Local anatomy around terminal ureter related to the anterior leaf of the vesicouterine ligament in radical hysterectomy. Eur J Obst Gynecol Reprod Biol 2019; 235: 66-70.

26. Shingo F, Kenji T, Noriomi M, et al. Precise anatomy of the vesico-uterine ligament for radical hysterectomy. Gynecol Oncol 2007; 104: 186-191.

27. Ceccaroni M, Clarizia R, Roviglione G, Ruffo G. Neuro-anatomy of the posterior parametrium and surgical considerations for a nerve-sparing approach in radical pelvic surgery. Surg Endosc 2013; 27: 4386-4394.

28. Ercoli A, Delmas V, Gadonneix P, et al. Classical and nerve-sparing radical hysterectomy: an evaluation of the risk of injury to the autonomous pelvic nerves. Surg Radiol Anat 2003; 25: 200-206.

29. Okabayashi H. Radical abdominal hysterectomy for cancer of the cervix uteri, modification of the Takayama operation. Surg Gynecol Obst 1921; 33: 335-341.

30. Ceccaroni M, Clarizia R, Bruni F, et al. Nerve-sparing laparoscopic eradication of deep endometriosis with segmental rectal and parametrial resection: the Negrar method. A single-center, prospective, clinical trial. Surg Endosc 2012; 26: 2029-2045. 


\section{Appendix 1}

\section{(Letters sent to participants)}

\section{Email sent to Group A participants in the study}

Dear Colleague,

We are conducting a study on how Obstetrics and Gynecology residents and attending physicians perceive the differences among the various types of radical hysterectomy, as described in the recent literature.

This is the reason why you are receiving the following three attached files:

- original Querleu-Morrow article [11] on the present classification of radical hysterectomy (pdf file),

- a numeric visual analog scale, graduated from 0 to 10 (Word file 1),

- a summary of the pertinent pelvic anatomy prepared by us for prompt consultation (Word file 2).

Please, after reading the article, insert a mark " $X$ ", as illustrated, underneath the numeric value of the attached visual analog scale that best reflects your degree of comprehension of the extent of parametrectomy characterizing each class of radical hysterectomy as deduced from the article and the summary of the pertinent pelvic anatomy provided.

How to fill out the numeric visual analog scale: as an example the numeric value of 4 is chosen as expression of the self-perceived level of understanding.

\begin{tabular}{lllllllllll}
\hline 0 & 1 & 2 & 3 & 4 & 5 & 6 & 7 & 8 & 9 & 10 \\
\hline & $\mathrm{X}$ \\
\hline
\end{tabular}

After inserting the check mark on the scale, please send Word file 1 back to us, within two months from the receipt of our email.

Answers received after the above time period are automatically excluded from the study and therefore considered as no answer.

Sincerely grateful for your cooperation, we'll keep you informed on the study results.

Best regards

\section{Email sent to Group B participants in the study}

Dear Colleague,

We are conducting a study on how Obstetrics and Gynecology residents and attending physicians perceive the differences among the various types of radical hysterectomy, as described in the recent literature.

This is the reason why you are receiving the following three attached files:

- original Querleu-Morrow article [11] on the present classification of radical hysterectomy (pdf file),

- a numeric visual analog scale, graduated from 0 to 10 (Word file 1),

- a summary of the pertinent pelvic anatomy prepared by us for prompt consultation (Word file 2),
- 10 graphs, prepared by us, as a didactic adjunct to the article (Word file 3).

Please, after reading the article, insert a mark " $X$ ", as illustrated, underneath the numeric value of the attached visual analog scale that best reflects your degree of comprehension of the extent of parametrectomy characterizing each class of radical hysterectomy as deduced from the article and the summary of the pertinent pelvic anatomy provided.

How to fill out the numeric visual analog scale: as an example the numeric value of 4 is chosen as expression of the self-perceived level of understanding.

\begin{tabular}{lllllllllll}
\hline 0 & 1 & 2 & 3 & 4 & 5 & 6 & 7 & 8 & 9 & 10 \\
\hline & $\mathrm{X}$ & & \multicolumn{1}{c}{}
\end{tabular}

After inserting the check mark on the scale, please send Word file 1 back to us, within two months from the receipt of our email.

Answers received after the above time period are automatically excluded from the study and therefore considered as no answer.

Sincerely grateful for your cooperation, we'll keep you informed on the study results.

Best regards

\section{Appendix 2}

(Summary of pertinent pelvic anatomy) $[7,20]$

\section{List of subperitoneal spaces}

A total of 17 virtual anatomical spaces, located underneath the pelvic peritoneum, are identified, of whom 6 are bilateral, found on the right and left side of the female pelvis and 5 are single and median; such spaces are surgically dissected during radical procedures for either gynecological cancers or deep pelvic endometriosis, a description of each of them according to the current literature is given:

- medial paravesical space (right and left MPVS) limits - dorsal: paracervix; ventral: ischium pubic branch; medial: vesico-uterine and vesico-vaginal ligaments (bladder pillars) and lateral wall of bladder; lateral: umbilical artery and umbilico-vesical fascia; caudal: iliococcygeus muscle; cranial: anterior leaf of the broad ligament,

- lateral paravesical space (right and left LPVS) limits - dorsal: obturator nerve, dihedral angle between anterior branch of the hypogastric artery and iliac vessels; ventral: as MPVS; medial: umbilical artery and umbilico-vesical fascia; lateral: external iliac vessels and obturator internus muscle; caudal: as MPVS; cranial: as MPVS,

- Yabuki space also known as fourth space (right and left) limits: dorsal: vaginal wall; ventral: posterior bladder wall; lateral: the vesico-vaginal ligament un- 
derneath the iuxtavesical-ureter; medial: vesico-vag inal space,

- medial pararettal space (right and left Okabayashi space, MPRS ) limits - dorsal: presacral fascia and sacrum bone; ventral: paracervix; medial: uterosacral and rectovaginal ligaments, rectal wall with its fascia, sacral attachments of uterosacral and rectovaginal ligaments (dorsal portions of rectal pillars); lateral: pelvic ureter and mesoureter; caudal: presacral fascia e sacral bone concavity; cranial: posterior leaf of the broad ligament,

- lateral pararettal space (right and left Latzko space, LPRS) limits - dorsal: as MPRS; ventral: as MPRS; medial: pelvic ureter and its meso merged with uterosacral and rectovaginal ligaments, rectal wall with its fascia, sacral attachments of uterosacral and rectovaginal ligaments (dorsal portions of rectal pillars); lateral: hypogastric vessels; caudal: as MPRS; cranial: as MPRS,

- ileo-lumbar space (right and left) limits - dorsal: piriformis muscle and sacral nervous roots; ventral: internal obturator muscle, ischium pubic branch; lateral both sides: pelvic wall and medial aspect of psoas muscle; medial: external and internal iliac vessels; caudal: pelvic floor; cranial: pelvic peritoneum. The description of this space is reported for completeness; in fact its dissection is not necessary for the purpose of radicality, but it is prepared sometimes during pelvic lymphadenectomy to reach the lymph nodes between the psoas muscle and the external iliac vessels or to gain access to the sacral plexus,

- prevesical space (Retzius space) limits - dorsal: ventral bladder wall, umbilical vessels; ventral: pubic symphysis, medial third of ischium pubic branches; lateral both sides: communicate with medial paravesical spaces; caudal: pubo-vesical ligaments, Santorini's venous plexus, proximal urethra, pubo-urethral fascia; cranial: peritoneum over the bladder dome,

- vesico-uterine space limits - dorsal: uterine cervix; ventral: posterior bladder wall; lateral both sides: vesico-cervical ligaments (cranial portions of bladder pillars); caudal: supravaginal septum (vesico-cervical ligament); cranial: bladder fold,

- vesico-vaginal space limits - dorsal: ventral vaginal wall with Halban's fascia; ventral: retrotrigonal bladder; lateral both sides: vesico-vaginal ligaments (caudal portion of bladder pillars); caudal: upper limit of bladder trigone; cranial: supravaginal septum,

- recto-vaginal space limits - dorsal: ventral rectal wall with its relative fascia; ventral: dorsal vaginal wall with Denonvilliers fascia; lateral both sides: recto-vaginal ligaments (caudal portions of rectal pillars); caudal: centrum tendineum perinei; cranial: pouch of Douglas,
- retrorectal space limits - dorsal: presacral fascia and sacrum bone; ventral: dorsal rectal wall with its relative fascia; lateral both sides: sacral attachments of uterosacral and recto-vaginal ligaments, pelvic ureter; caudal: Waldeyer recto-sacral fascia and levator plate; cranial: pelvic peritoneum.

\section{Parametrium}

Regarding cervical anatomy, in primis no limit exists between the tissue around the cervix and that around the upper vagina [21].

In secundis the structure around the cervix and upper vagina, which we refer to as parametrium, has been divided in the following 4 parts, according to the Terminologia Anatomica [7]: ventral (anterior), right and left lateral, and dorsal (posterior).

In order to outline the right and left ventral parametrium, the following anatomic spaces (a total of 8) need to be artificially created, by surgical dissection [10, 22-24]:

- the right and left paravesical space, which is divided into medial and lateral by the lateral ligament of the bladder (umbilical ligament),

- the vesico-uterine and vesico-vaginal spaces, both single and median, separated by the vesico-vaginal septum,

- the right and left Yabuki space.

The right and left ventral parametrium is made of 2 parts: one is the vesicouterine ligament, cranial and medial to the ureter, and the other is the vesicovaginal ligament, caudal and lateral to the ureter, also called the posterior leaf of the vesicouterine ligament by Japanese authors [25, 26], which contains the bladder autonomic nerve. Both ligaments separate the vesicouterine and vesicovaginal space from the medial paravesical space.

In order to outline the right and left dorsal parametrium the following anatomic spaces (a total of 5) need to be surgically developed [27]:

- the rettovaginal space, single and median,

- the right and left pararettal space, divided into medial, Okabayashi's space, and lateral, Latzko space, by the retroligamentous portion of the pelvic ureter with its mesoureter underneath. Okabayashi's space is also known as the sacrouterine space, according to Cibula [11], and it is not developed in type C2 radical hysterectomy, whereas its development is absolutely mandatory in type $\mathrm{C} 1$ and $\mathrm{B}$ and may be omitted in type $A$ radical hysterectomy,

- the retrorettal space, single and median, whose lateral limits are made by the sacral attachments of the sacrouterine and rettovaginal ligaments, which need to be identified in class $\mathrm{C} 2$ radical hysterectomy.

The dorsal parametrium is made of the rectouterine cranially and the rectovaginal ligament caudally; it con- 
tains part of the pelvic autonomic nerves, which can be preserved by developing the medial pararettal space.

Finally the lateral parametrium or paracervix is outlined by the development of all the above-mentioned spaces; it contains lymphatic channels and lymph nodes, arterial and venous vessels, the infraligamentous ureter, adipose tissue, and caudally to the deep uterine vein the hypogastric plexus [7, 10, 24, 28-30].

\section{Anatomical landmarks}

The following anatomic landmarks have been identified to help surgeons define the limit of parametrial resection:

- the pelvic ureter, in relationship with the broad ligament, may be divided into three sections, defined as:

- the retroligamentous portion - it is adherent to the posterior leaf of the broad ligament and represents the medial limit of the lateral pararectal space,

- the infraligamentous portion - it runs inside the lateral parametrium, underneath the uterine artery,

- the preligamentous or iuxtavesical portion - it runs inside the ventral parametrium and divides it into its cranial and caudal part;

- the uterine artery origin from the hypogastric artery - represents the most external and cranial limit of the lateral parametrium;
- the deep uterine vein - separates the cranial from the caudal portion of the lateral parametrium, which contains the autonomic nerves;

- the middle rectal artery - it is part of the rectal stalk and crosses the lateral portion of the retto-vaginal space, the rectal branches of the hypogastric plexus are located underneath this artery;

- the middle and inferior vesical vein - located in caudal portion of ventral parametrium, in proximity with the bladder autonomic nerve branches;

- the inferior, middle and superior vesical artery cross the medial paravesical spaces;

- the hypogastric nerve - it connects the superior with the inferior hypogastric plexus; it is often visible through the posterior leaf of the broad ligament underneath the retroligamentous portion of the pelvic ureter and must be dissected laterally during the preparation of Okabayashi's space; it represents the most cranial nerve to be preserved in class $\mathrm{C} 1$ radical hysterectomy.

\section{Supporting information legend}

Appendix 1

Letters sent to participants

Appendix 2

Summary of pertinent pelvic anatomy 